\title{
Development and testing of a Jatropha fruit shelling process for shell-free kernel recovery in biodiesel production
}

\begin{abstract}
Achieving shell-free kernel recovery from Jatropha fruits is important to improve oil yield and oil quality during oil extraction in biodiesel production. A shelling process with two stages of cracking and separation to remove the shells completely and husks partially was designed. Both stages used double-level cracking rollers and a blower with ducting as a separation unit. For the first, the performance was evaluated using five different roller clearances $(9.5 \mathrm{~mm}, 10.0 \mathrm{~mm}, 10.5 \mathrm{~mm}, 11.0 \mathrm{~mm}$ and $11.5 \mathrm{~mm})$ with a combination of five blower air speeds $\left(8.5 \pm 0.5 \mathrm{~m} \mathrm{~s}^{-1}, 9.0 \pm 0.6 \mathrm{~m} \mathrm{~s}-1,9.5 \pm 0.5 \mathrm{~m} \mathrm{~s}-1,10.0 \pm 0.4 \mathrm{~m} \mathrm{~s}-1\right.$ and $10.5 \pm 0.5 \mathrm{~m} \mathrm{~s}^{-1}$ ). A roller clearance of $10.5 \mathrm{~mm}$ and air speed of $10.0 \pm 0.4 \mathrm{~m} \mathrm{~s}-1$ were selected as the optimal conditions with the highest separation efficiency between kernels and shells at $94.59 \%$. The shells and husks achieved $95.88 \%$ and $12.20 \%$ removal respectively while kernel recovery achieved $98.65 \%$. For the second stage, the performance was evaluated using five different roller clearances $(5.0 \mathrm{~mm}, 5.5 \mathrm{~mm}, 6.0 \mathrm{~mm}, 6.5 \mathrm{~mm}$ and $7.0 \mathrm{~mm})$ with a combination of five blower air speeds $\left(6.5 \pm 0.4 \mathrm{~m} \mathrm{~s}^{-1}, 7.0 \pm 0.2 \mathrm{~m} \mathrm{~s}-1,7.5 \pm 0.4 \mathrm{~m} \mathrm{~s}^{-1}, 8.0\right.$ $\pm 0.2 \mathrm{~m} \mathrm{~s}-1$ and $8.5 \pm 0.5 \mathrm{~m} \mathrm{~s}-1)$. At the optimal conditions, with a roller clearance of 6.0 $\mathrm{mm}$ and air speed of $7.5 \pm 0.4 \mathrm{~m} \mathrm{~s}-1$, the maximum separation efficiency was $97.69 \%$. Total shell and husk removal achieved for the stages were $100.00 \%$ and $45.46 \%$ respectively. A total of $2.40 \%$ kernels were lost.
\end{abstract}

Keyword: Shell-free kernel recovery; Jatropha fruits; Biodiesel production 